\title{
Childhood cancers in Zambia before and after the HIV epidemic
}

\author{
Chifumbe Chintu, Uma H Athale, P S Patil
}

\begin{abstract}
Human immunodeficiency virus (HIV) related cancers in children are not as common and as well described as in adults. An HIV epidemic has been prevalent in Zambia since 1983-1984. To study the effect of the epidemic on the epidemiology of cancers in children a retrospective study was undertaken at the University Teaching Hospital (UTH), Lusaka, Zambia. All the histopathological records from 1980 to 1992 were reviewed and all cases of cancers in children less than 14 years of age were analysed. In order to define the effect of the HIV epidemic, the epidemiological features of various childhood cancers occurring before (during the years 1980-1982) and after (during the years 1990-1992) the onset of the HIV epidemic were compared. A significant increase in the occurrence of total childhood cancers was found. This is mostly due to a highly significant increase in the incidence of paediatric Kaposi's sarcoma $(p=0.000016)$, which is causally related to HIV infection, and a significant increase in the incidence of retinoblastoma $(p=0.02)$, which has an unknown relation to HIV infection. Though not yet statistically significant, there has also been a gradual and sustained increase in the incidence of nonHodgkin's lymphoma, nasopharyngeal carcinoma, and rhabdomyosarcoma. There has been a significant reduction in the incidence of Burkitt's lymphoma. A prospective in depth epidemiological study of HIV related childhood cancers in Africa is urgently needed.

(Arch Dis Child 1995; 73: 100-105)
\end{abstract}

Keywords: childhood cancers, HIV/AIDS, Kaposi's sarcoma, retinoblastoma, non-Hodgkin's lymphoma, rhabdomyosarcoma.

Aggressive Kaposi's sarcoma and nonHodgkin's lymphoma have been well described and are causally related to human immunodeficiency virus (HIV) infection in adults. ${ }^{1}$ However the role of HIV infection in causing various childhood cancers and its effect on their epidemiology have not been as well described as in adults. ${ }^{2}$ Reports are now emerging which indicate that the epidemiology of childhood cancers is also being affected by the HIV/AIDS epidemic. ${ }^{2-4}$

An HIV epidemic has been prevalent in Zambia since 1983-1984. In order to study the effect of the HIV epidemic on the epidemiology of cancers in children, we undertook a retrospective study at the University Teaching Hospital (UTH), Lusaka, Zambia. This paper describes our experience with childhood malignancies in Zambia over the last 13 years.

\section{Methods}

Zambia is a sub-Saharan African country, with a population of 8.6 million. ${ }^{5}$ The University Teaching Hospital (UTH), situated in the capital city of Lusaka, is a national referral centre with a bed capacity of 1800 and bed occupancy of over $100 \%$. The histopathology department of UTH receives surgical specimens from all over Zambia, with the exception of copper mines hospitals, representing about $77 \%$ of the total paediatric population of Zambia. $^{6}$

All the histopathological records over the period from 1st January 1980 until 31st December 1992 were reviewed. Cases of malignancies occurring in the paediatric age range of 0 to 14 years were analysed and the sex, clinical features, and site of biopsy were noted. Duplication of results and cases with inadequate or doubtful information of age or diagnosis were excluded.

The country census figures of 1980 and 1990 and their projections were used for analysis. ${ }^{6}$ Statistical analysis was performed using the $\chi^{2}$ test.

\section{Results}

During the stated 13 year study period 698 cases of paediatric malignancies were diagnosed at the UTH, with a crude annual incidence of 21.89 cases/million children. Table 1 shows the annual occurrence of different childhood cancers. Overall, lymphoma was the commonest reported childhood malignancy $(36.95 \%)$, followed by retinoblastoma $(12 \cdot 46 \%)$ and Kaposi's sarcoma $(12 \cdot 17 \%)$.

To study the impact of the HIV epidemic we compared the epidemiology of different childhood cancers occurring a decade apart: during the pre-HIV epidemic period of 1980-1982 
Table 1 Childhood malignancies 1980-1992

\begin{tabular}{|c|c|c|c|c|c|c|c|c|c|c|c|}
\hline Year & $\begin{array}{l}\text { Total } \\
\text { Malignancies }\end{array}$ & $\begin{array}{l}\text { Non- } \\
\text { Hodgkin's } \\
\text { lymphoma }\end{array}$ & $\begin{array}{l}\text { Burkitt's } \\
\text { lymphoma }\end{array}$ & $\begin{array}{l}\text { Hodgkin's } \\
\text { lymphoma }\end{array}$ & Leukaemia & Retinoblastoma & $\begin{array}{l}\text { Kaposi's } \\
\text { sarcoma }\end{array}$ & $\begin{array}{l}\text { Wilms' } \\
\text { tumour }\end{array}$ & Rhabdomyosarcoma & $\begin{array}{l}\text { Nasopharyngeal } \\
\text { carcinoma }\end{array}$ & Others \\
\hline $\begin{array}{l}1980 \\
1981 \\
1982 \\
1983 \\
1984 \\
1985 \\
1986 \\
1987 \\
1988 \\
1989 \\
1990 \\
1991 \\
1992\end{array}$ & $\begin{array}{l}29 \\
32 \\
53 \\
50 \\
56 \\
53 \\
59 \\
49 \\
51 \\
66 \\
58 \\
75 \\
67\end{array}$ & $\begin{array}{r}3 \\
5 \\
16 \\
10 \\
13 \\
9 \\
8 \\
6 \\
10 \\
6 \\
18 \\
13 \\
12\end{array}$ & $\begin{array}{r}6 \\
4 \\
10 \\
5 \\
8 \\
10 \\
6 \\
8 \\
5 \\
13 \\
6 \\
3 \\
3\end{array}$ & $\begin{array}{l}2 \\
3 \\
1 \\
3 \\
5 \\
6 \\
1 \\
3 \\
- \\
4 \\
3 \\
5 \\
2\end{array}$ & $\begin{array}{l}3 \\
3 \\
4 \\
2 \\
3 \\
2 \\
4 \\
- \\
- \\
4 \\
2 \\
5 \\
2\end{array}$ & $\begin{array}{r}1 \\
1 \\
5 \\
5 \\
9 \\
4 \\
13 \\
6 \\
9 \\
10 \\
9 \\
9 \\
6\end{array}$ & $\begin{array}{r}2 \\
0 \\
1 \\
3 \\
6 \\
5 \\
3 \\
6 \\
8 \\
12 \\
11 \\
16 \\
12\end{array}$ & $\begin{array}{l}3 \\
2 \\
1 \\
2 \\
- \\
3 \\
3 \\
3 \\
3 \\
2 \\
1 \\
3 \\
2\end{array}$ & $\begin{array}{l}2 \\
-1 \\
2 \\
3 \\
1 \\
2 \\
3 \\
2 \\
2 \\
2 \\
6 \\
4\end{array}$ & $\begin{array}{l}1 \\
-1 \\
1 \\
2 \\
3 \\
1 \\
2 \\
2 \\
1 \\
1 \\
1 \\
2\end{array}$ & $\begin{array}{r}6 \\
14 \\
11 \\
17 \\
8 \\
10 \\
18 \\
10 \\
11 \\
13 \\
4 \\
14 \\
21\end{array}$ \\
\hline Total: & 698 & 129 & 87 & 38 & 34 & 87 & 85 & 28 & 30 & 18 & 157 \\
\hline
\end{tabular}

and after the epidemic was established (1990-1992). Table 2 shows the comparative prevalence of different malignancies between these periods. There was an increase in the occurrence of total childhood cancers during the years $1990-1992(p=0.03)$. An increase in the occurrence of Kaposi's sarcoma $(p=0.000016)$ and retinoblastoma $(p=0.02)$ was also noticed. There was a decrease in the occurrence of Burkitt's lymphoma $(p=0 \cdot 05)$. No difference in prevalence of other cancers was observed, although a three fold increase in the occurrence of rhabdomyosarcoma was observed.

\section{Non-Hodgkin's lymphoma}

In all, 129 cases $(18.48 \%)$ were diagnosed as having non-Hodgkin's lymphoma. The age range was six months to 14 years (average $8 \cdot 4$ years) and the male to female ratio was $2 \cdot 36: 1$. The peak incidence was between six and 10 years $(48 \%)$. Thirty six per cent of the patients presented with nodal lymphoma while 59\% had extranodal presentation. In $10 \%$ of the patients the site of biopsy was unknown. Among the extranodal sites osseous involvement, especially of facial bones, was the commonest $(35 \cdot 7 \%)$, followed by abdominal $(20.9 \%)$. The epidemiological features of nonHodgkin's lymphoma occurring during the period of 1990-1992 differ from those seen during 1980-1982. The average age at diagnosis has reduced from 8.69 years during $1980-1982$ to $7 \cdot 92$ years in $1990-1992$; the male predominance has declined from $5: 1$ to 2.36:1; and the disease has become more extranodal and much more aggressive $(64 \%$ of the cases were high grade lymphoma) in recent years. Also there were three cases of ovarian lymphoma in the post-HIV period, which had not been seen during the pre-HIV era. None of these differences, however, was statistically significant.

\section{Burkitt's lymphoma}

A total of 87 cases with an age range of six months to 14 years (average age 6.56 years) and a male to female ratio of $1 \cdot 55: 1$ was diagnosed as Burkitt's lymphoma. There were two infants less than 1 year old and seven less than 2 years. Peak incidence was between five and 10 years $(49 \%)$ and the majority $(52 \cdot 87 \%)$ presented with jaw tumour. Apart from decrease in the incidence no difference in the epidemiological features of Burkitt's lymphoma was noticed.

\section{Hodgkin's lymphoma}

There were in all 37 cases diagnosed as Hodgkin's lymphoma over 13 years period. The age range was 2 to 14 years, with an average of 8.07 years, and the male to female ratio was $8 \cdot 25: 1$. There were four children less than 5 years old $(10.81 \%), 17$ between 6 and 10 years $(45.95 \%)$, and 14 over 10 years $(37.83 \%)$. In two children the exact age was not known. In the majority of patients (33/37) the presentation was nodal; skin and bone involvement was noted in one case each. In two patients the site of biopsy was not known. Mixed cellularity was the commonest histopathological type $(54.05 \%)$, followed by lymphocytic predominant and lymphocytic depletion types $(13 \cdot 51 \%$

Table 2 Comparative prevalence of different malignancies between periods 1980-1982 and 1990-1992

\begin{tabular}{|c|c|c|c|c|c|c|c|}
\hline \multirow[b]{2}{*}{ Malignancy } & \multicolumn{3}{|c|}{ 1980-1982 (pre-HIV epidemic) } & \multicolumn{3}{|c|}{ 1990-1992 (post-HIV epidemic) } & \multirow[b]{2}{*}{ p Value } \\
\hline & Total No & Percentage & Prevalence & Total No & Percentage & Prevalence & \\
\hline Total & 114 & 100 & $17 \cdot 1$ & 200 & 100 & $22 \cdot 1$ & 0.03 \\
\hline All lymphomas & 48 & $42 \cdot 1$ & $7 \cdot 2$ & 65 & 32.5 & $7 \cdot 1$ & NS \\
\hline Non-Hodgkin's lymphoma & 25 & 21.92 & 3.7 & 44 & $22 \cdot 0$ & $4 \cdot 8$ & NS \\
\hline Burkitt's lymphoma & 18 & $15 \cdot 78$ & $2 \cdot 7$ & 11 & $5 \cdot 5$ & $1 \cdot 2$ & 0.05 \\
\hline Hodgkin's lymphoma & 6 & $5 \cdot 26$ & 0.9 & 10 & $5 \cdot 0$ & $1 \cdot 1$ & NS \\
\hline Retinoblastoma & 7 & $6 \cdot 14$ & $1 \cdot 0$ & 26 & $13 \cdot 0$ & $2 \cdot 8$ & 0.02 \\
\hline Kaposi's sarcoma & 3 & $2 \cdot 63$ & 0.4 & 39 & $19 \cdot 5$ & $4 \cdot 2$ & 0.000016 \\
\hline Wilms' tumour & 8 & $7 \cdot 01$ & $1 \cdot 2$ & 6 & 3.0 & 0.66 & NS \\
\hline Nasopharyngeal carcinoma & 2 & 1.75 & 0.3 & 4 & $2 \cdot 0$ & 0.44 & NS \\
\hline All sarcomas & 15 & $13 \cdot 15$ & $2 \cdot 25$ & 21 & $10 \cdot 5$ & $2 \cdot 32$ & NS \\
\hline Rhabdomyosarcoma & 3 & 2.63 & 0.45 & 12 & $6 \cdot 0$ & $1 \cdot 32$ & NS \\
\hline Osteosarcoma & 1 & 0.87 & 0.15 & 2 & $1 \cdot 0$ & 0.22 & NS \\
\hline Soft tissue sarcoma & 9 & $7 \cdot 89$ & 1.35 & 3 & 1.5 & 0.33 & NS \\
\hline
\end{tabular}

Prevalence is per 1000000 children ( $<14$ years)/year. 
Table 3 Age and sex distribution of patients with retinoblastoma. Values are numbers of cases

\begin{tabular}{lllrll}
\hline & \multicolumn{4}{l}{ Age (in years) } & \\
\cline { 2 - 5 } Sex & $0-1$ & $2-5$ & $>5$ & $?$ & Total \\
\hline Male & 2 & 33 & 11 & 4 & 50 \\
Female & 2 & 34 & 1 & - & 37 \\
Total: & 4 & 67 & 12 & 4 & 87
\end{tabular}

each), and nodular sclerosis $(5 \cdot 4 \%)$. In six patients $(16 \cdot 21 \%)$ the histopathological type was not specified. In the year 1990, a 2 year old girl with generalised lymphadenopathy was found to have coexistent lymphocytic depletion type of Hodgkin's lymphoma and Kaposi's sarcoma lesions in the same lymph node mass.

\section{Wilms' tumour}

In all 36 patients were diagnosed to have Wilms' tumour. Age ranged from six months to 10 years. There was a female predominance with a male to female ratio of 0.52 . There were six infants less than 1 year, 12 children between 2 and 5 years, and seven between 6 and 10 years. In one child the exact age was not specified. No difference in the incidence or epidemiological features were noted in the pre-HIV and the post-HIV period.

\section{Nasopharyngeal carcinoma}

Eighteen cases of nasopharyngeal carcinoma were diagnosed. Age range was 9 to 14 years, with majority of patients over 10 years of age. The male to female ratio was $1 \cdot 25$.

\section{Kaposi's sarcoma}

The incidence of Kaposi's sarcoma in the beginning of 1980 was negligible, almost nonexistent. Thereafter, there was a significant increase in the occurrence of paediatric Kaposi's sarcoma ( $p=0 \cdot 000016)$. Eighty five cases of Kaposi's sarcoma were diagnosed in children aged 14 years or less. Age range was from seven months to 14 years, with an average of 5.62 years; the male to female ratio was $1 \cdot 76: 1$. Fifty nine per cent of the patients were less than 5 years of age. The peak incidence occurred between one and two years

\section{Retinoblastoma}

In all, 87 patients were diagnosed as having retinoblastoma. There was a statistically

Table 4 Occurrence of various childhood cancers, as percentages of total childhood cancers over different periods of time in Zambia in comparison with cancers in Kenya

\begin{tabular}{|c|c|c|c|c|}
\hline & \multicolumn{3}{|c|}{ Zambia (0-14 years) } & \multirow{2}{*}{$\begin{array}{l}\text { Kenya } \\
(0-15 \text { years) } \\
(1968-1980)\end{array}$} \\
\hline & $1968-1972$ & $1980-1982$ & $1990-1992$ & \\
\hline All lymphomas & $37 \cdot 6$ & $42 \cdot 1$ & $32 \cdot 5$ & $49 \cdot 3$ \\
\hline Non-Hodgkin's lymphoma & $7 \cdot 6$ & $21 \cdot 9$ & $22 \cdot 0$ & $16 \cdot 2$ \\
\hline Burkitt's lymphoma & $24 \cdot 1$ & $15 \cdot 8$ & $5 \cdot 5$ & $24 \cdot 1$ \\
\hline Hodgkin's lymphoma & $5 \cdot 7$ & $5 \cdot 3$ & $5 \cdot 0$ & 8.9 \\
\hline Retinoblastoma & $8 \cdot 9$ & $6 \cdot 1$ & $13 \cdot 0$ & $7 \cdot 8$ \\
\hline Kaposi's sarcoma & $3 \cdot 2$ & $2 \cdot 6$ & $19 \cdot 0$ & 1.8 \\
\hline Wilms' tumour & $8 \cdot 2$ & $7 \cdot 0$ & $3 \cdot 0$ & $8 \cdot 1$ \\
\hline Nasopharyngeal carcinoma & 0 & $1 \cdot 8$ & $2 \cdot 0$ & $3 \cdot 8$ \\
\hline Rhabdomyosarcoma & - & $2 \cdot 6$ & $6 \cdot 0$ & $2 \cdot 7$ \\
\hline Soft tissue sarcoma & - & $13 \cdot 2$ & $10 \cdot 5$ & $6 \cdot 3$ \\
\hline
\end{tabular}

significant increase in the incidence of retinoblastoma during the post-HIV period $(p=0 \cdot 02)$. Apart from this no other difference in the epidemiological features was noted. Table 3 shows the age and sex related occurrence of retinoblastoma over the period 1980-1992. The age ranged from 3 months to 10 years, with an average of 3.35 years. The male to female ratio was $1 \cdot 3: 1$. Most of our patients were diagnosed after their first birthday. No bilateral disease was reported.

\section{Sarcomas}

In all there were 70 cases with this diagnosis.

Ewing's sarcoma was diagnosed in four patients. There was a total of 14 patients with osteosarcoma with an age range of seven to 14 years (six children between five and 10 years, seven of more than 11 years, and one whose age was unknown), and the male to female ratio was $0 \cdot 8$.

Rhabdomyosarcoma was diagnosed in 30 patients. The incidence of this tumour appears to have increased over the decade, though the increase is not statistically significant at present. We are also recently seeing rhabdomyosarcoma originating from the vagina. Four out of 12 cases in the post-HIV epidemic period presented with vaginal rhabdomyosarcoma, whereas there were none in the pre-HIV period. The age ranged from 15 months to 14 years (with an average of 5.42 years) Sixteen children were less than 5 years old, seven between 6 and 10, and three were over 11 years. There was female predominance, with a male to female ratio of 0.625 .

There were 26 other sarcomas including leiomyosarcoma and undifferentiated sarcoma, and no difference in the epidemiological features was observed between the pre-HIV and the post-HIV epidemic periods.

\section{Discussion}

Cancer is a rare disorder in childhood both in immunocompetent and immunodeficient children. While $13-15 \%$ of the HIV infected adults present with malignancy as their AIDS indicator disease, only $0 \cdot 5-2 \cdot 1 \%$ of children present with malignancy. ${ }^{7-9}$

Non-Hodgkin's lymphoma, either as a systemic disease or as a primary CNS tumour, has been the most common cancer in association with HIV/AIDS in adults as well as in children. ${ }^{2910}$ Recently a 360-fold increase of nonHodgkin's lymphoma in HIV infected patients less than 19 years of age has been reported. ${ }^{11}$

Non-Hodgkin's lymphoma was the commonest childhood malignancy in Zambia even in the pre-HIV era, in contrast with the neighbouring countries. As shown in table 4, the incidence of this disease appears to have been increasing gradually over the years in Zambia, ${ }^{3}{ }^{12-14}$ although the increase is not at present statistically significant. In addition, there have been differences in the epidemiological features of the condition over the periods compared. Extranodal involvement has been seen more commonly than nodal in 
recent years and there has been an increased incidence of high grade lymphoma. There have been more females affected, and ovarian lymphoma has been seen for the first time in the recent past. The apparent absence or rarity of CNS lymphoma (or any CNS malignancy) in Zambia is obviously a reflection of the inadequate neurosurgical services in Zambia.

Our study is based on the general population rather than selected HIV infected children and we do not know the HIV status of all these patients. Hence it is unclear whether the increase in the incidence and the observed changes in the epidemiological features of nonHodgkin's lymphoma are related to the current HIV epidemic in the country.

Burkitt's's lymphoma is endemic in tropical Africa. ${ }^{1415}$ Part of northern Zambia, especially Luapula province, falls into this belt of endemic Burkitt's lymphoma and most of our cases come from Luapula province. The incidence of Burkitt's lymphoma in Zambia has been reduced from $24 \cdot 1 \%$ of total cancers in $1968-1972$ to $15.8 \%$ in $1980-1982$, and to $5.5 \%$ in $1990-1992$ (table 4 ). The reduction is statistically significant $(p=0.05)$. With the available data we cannot offer an explanation for this finding.

The interaction of Epstein-Barr virus, HIV infection, and lymphoproliferation is well documented.21617 In African countries like Zambia where both these viruses are highly prevalent and where co-infection in a single host is common, their mutual suppressive or stimulatory effects could cause significant alteration in the disease pattern caused by either virus in isolation. One cannot say if this has led to the decrease in the incidence of Burkitt's lymphoma. There is a need for a more extensive epidemiological study.

HIV infected patients with Hodgkin's lymphoma present more commonly with systemic symptoms, and often with advanced disease and involvement of extranodal sites. Bone marrow invasion is common and so is cytopenia before treatment. Aggressive disease in the histopathological forms of mixed cellularity and nodular sclerosis types are common. ${ }^{2}$

The incidence and epidemiological features of Hodgkin's lymphoma have remained almost constant over the years in Zambia. ${ }^{313}$ The incidence is lower than in the neighbouring countries. ${ }^{12} 14$ We have also noticed a marked male predominance of $8 \cdot 6: 1$ in contrast to the findings of Kungu', 12 and $54 \%$ of our patients had mixed cellularity type of Hodgkin's lymphoma. These differences seem to be due to racial/genetic rather than HIV related. However, the case of Hodgkin's lymphoma and Kaposi's sarcoma in the same lymph node mass is worth mentioning.

In our opinion the lymphomas (and other lymphadenopathic cancers) are underdiagnosed, especially with the high prevalence of HIV related tuberculosis in the country. ${ }^{18}$ Because of several diagnostic restraints common to developing countries, most of the lymphadenopathies are currently diagnosed and treated clinically as tuberculosis without histopathological confirmation. If all the lymphadenopathies in children were to be biopsied we might see a different epidemiological picture.

The incidence of Wilms' tumour was second to lymphoma in earlier reports from Zambia and Kenya and was first in a Tanzanian study. ${ }^{3}$ 12-14 This tumour has now been supplanted by retinoblastoma and Kaposi's sarcoma in Zambia.

Kaposi's sarcoma is presumed to be relatively rare in the paediatric HIV infected population, with 21 cases reported as the AIDS defining illness among 4249 children with AIDS registered by the Centers for Disease Control, and only one case among 1321 patients from the Italian register for HIV infection in children. ${ }^{89}$ This may be an underestimation of these incidences because figures probably did not consider the cases of Kaposi's sarcoma which developed after the diagnosis of HIV infection or AIDS. Despite this, it implies a high incidence of Kaposi's sarcoma in HIV infected children (757 to 4942 cases per million HIV infected children).

From an almost non-existent occurrence in the early 1980s, Kaposi's sarcoma has emerged as a significant childhood malignancy in Zambia, constituting about $20-25 \%$ of total childhood cancers in the early 1990s. The significant increase in the incidence of childhood Kaposi's sarcoma was noted since 1987. This coincides with the advent of the HIV epidemic in the population and the increased rates of paediatric HIV infection, mainly through mother to child transmission but also through blood and blood product transmission. 4

A similar but more profound increase in atypical and aggressive Kaposi's sarcoma in adults has been noted in Zambia since 1983. ${ }^{19}$ In a separate study at UTH, $70 \%$ of HIV seropositivity was noted in children with Kaposi's sarcoma. ${ }^{4}$ Unlike in adults, HIV associated Kaposi's sarcomas in children do not follow a particular pattern. ${ }^{24}$

The incidence of retinoblastoma has increased gradually over the decade. This increase is statistically significant $(p=0.02)$. The diagnosis of retinoblastoma was commonly made after the first year of life, mostly between 2 and 5 years of age. Although metastasis and local extension of the disease was common at the time of diagnosis, no incidence of bilateral disease was recorded. The increase in the incidence of retinoblastoma over the HIV era is difficult to relate causally to HIV or AIDS. More epidemiological studies are needed.

An increased incidence of soft tissue tumours has been observed in HIV infected children. 20 Leiomyomas and leiomyosarcomas are reported more frequently than other types of sarcoma. Although no statistically significant change in the incidence of soft tissue sarcomas has been observed, we have noticed a threefold increase in the incidence of rhabdomyosarcoma. Vaginal rhabdomyosarcoma has also been seen since 1990; this was never seen before. 
Although not significant, there also appears to have been an increase in the incidence of nasopharyngeal carcinoma over the years. The incidence of this cancer in Zambia is lower than in the neighbouring countries. ${ }^{12}$ Although the difference in the incidence of nasopharyngeal carcinoma has not been significant over the decade, in comparison to previous reports in Zambia during the period 1968-1972 there has been a substantial increase $(p=0 \cdot 04) .^{313}$

The epidemiology of other cancers does not seem to have been grossly affected by the HIV epidemic.

Thus the HIV epidemic seems to have had an impact on the epidemiology of childhood cancers in Zambia. Over the decade under review, there has been a significant increase in the incidence of total paediatric malignancies in Zambia. This is mostly the result of a highly significant increase in the incidence of paediatric Kaposi's sarcoma $(p=0.000016)$, which is causally related to HIV infection, and to a significant increase in the incidence of retinoblastoma $(p=0.02)$, which has an unknown relation to HIV infection; although not yet statistically significant, a gradual sustained increase in the incidence of nonHodgkin's lymphoma, nasopharyngeal carcinoma, and rhabdomyosarcoma have also contributed to the overall increase. There has been a significant reduction in the incidence of Burkitt's lymphoma. However, this has not been great enough to counteract the increment caused by other cancers.

Our study was based on the general population and not only on HIV infected children. A prospective in depth epidemiological study of HIV related cancers in Africa is urgently needed.

1 Bigger RJ, Horm J, Lubin JH, Goedent J, Greene $\mathrm{MH}$, Fraumeni JF. Cancer trends in population at risk of acquired immunodeficiency syndrome. $f$ Natl Cancer Inst 1985; 74: 793-7.

2 Mueller BU, Shad AT, Magrath IT, Horowitze ME. Malignancies in children with HIV infection. In: Pizzo PA, Wilfert CM, eds. Pediatric AIDS. The challenge of HIV infection in infants, children and adolescents, 2nd ed. Baltimore: Williams and Wilkins, 1994: 603-22.

3 Patil PS, Elem B, Gwavava MJT, Urban MI. The pattern of paediatric malignancy in Zambia (1980-1989): a hospita based histopathological study. F Trop Med Hyg 1992; 95: $124-7$.

4 Athale UH, Patil PS, Chintu C, Elem B. Influence of HIV epidemic on the incidence of Kaposi's's sarcoma in Zambian children. $f$ Acquir Immune Defic Syndr Hum Retrovirol 1995; 8: 96-100.

5 Gaisie K, Cross AR, Nsemukila G. Zambian demographic and health survey 1992. Columbia, MA: Macro International Inc, 1992.

6 Central statistics office. 1990 Census of population, housing and agriculture. Lusaka: Central Statistical Office, Republic of Zambia, 1990.

7 US Department of Health and Human Services, Center for Disease Control and Prevention. HIVIAIDS surveillance report. Rockville, Maryland: CDC, 1993; Feb 1-23.

8 US Department of Health and Human Services, Center for Disease Control and Prevention. Cumulative number of malignancies as an AIDS-indicative disease in children. Rockville, Maryland: CDC, 1993. (AIDS public information dataset.)

9 Arico M, Caselli D, D'Argenio P, et al. Malignancies in children with human immunodeficiency virus type 1 infection. Cancer 1991; 68: 2473-7.

10 Epstein LG, DiCarlo FJ, Joshi VV, et al. Primary lymphoma of the central nervous system in children with acquired immunodeficiency syndrome. Pediatrics 1988; 82: 355-63.

11 Beral V, Peterman T, Berkelman R, Jaffe H. AIDS-associated non-Hodgkin's lymphoma. Lancet 1991; 337: 805-9.

2 Kungu' A Childhood cancers in Kenya: a histopathologica and epidemiological study. $E$ Afr Med $f 1984 ; 61: 11-24$

Naik KG. Cancers in African children. Med $\mathcal{F}$ Zambia 1975 9: 52-6.
14 Parkin DM, Stiller CA, Draper GA, Bieber CA, Terracini $\mathrm{B}$, Young $\mathrm{JL}$, eds. International incidence of childhood cancers. No 87. Lyon: IARC Scientific Publications, 1988:387-90.

15 Olivery CLM. Lymphomas and leukemias. Part 1: tropical Africa. In: Luzzatto L, ed. Clinics in haematology: haematology in tropical areas, vol 10. London: W B Saunders Co 1981:873-93.

16 Stein ME, Spencer E, Dancey R, Bezwoda WR. Biology of disease and clinical aspects of AIDS associated lymphoma: a review. E Afr Med f 1994; 71: 219-22.

$17 \mathrm{Katz}$ BZ, Berkman AB, Shapiro ED. Serologic evidence of active Epstein-Barr virus infection and Epstein-Barr associated lymphoproliferative disorders of children with acquired immunodeficiency syndrome. $f$ Pediatr 1992; 120: $228-32$.

18 Elliot AM, Luo N, Tembo G. Impact of HIV on tuberculosis in Zambia: a cross sectional study. $B M \mathcal{F}$ 1990; 301: 412-5.

19 Bayley A.C. Aggressive Kaposi's's sarcoma in Zambia. Lancet 1984; i: 1318-20.

20 Mueller BV, Butler KM, Feuerstein IM, et al. Smooth muscle tumours in children with human immunodeficiency virus infection. Pediatrics 1992; 90: 460-3.

\section{Commentary}

The Pan-African paediatric oncology meeting, held in Stellenbosch University in South Africa in 1994, highlighted many problems which excellent paediatricians face throughout Africa in dealing with childhood cancer.

These diseases are becoming more of a problem as the conventional mass killers of infection and malnutrition are controlled in many of the developing countries. The consensus view expressed at this meeting, sponsored by the International Society of Paediatric Oncology, was that population based tumour registration was an important step towards understanding the extent and depth of cancer as a problem within each society. Cancer care clearly had to be weighed against all other demands on limited resources.

In many countries the huge impact of the human immunodeficiency virus has highlighted dramatic changes in malignancies, and thrown up some very interesting possible associations, not just Kaposi's sarcoma, but as in the Zambian work, a possible rise in the incidence of other tumours such as retinoblastoma and a decline in other lymphomas. This is a very important study, and the authors are to be encouraged to continue their invaluable work.

It is important, however, to express some caution in interpreting too much from cases referred to a single institution, even if it is thought that that hospital caters for a considerable proportion of the population. Only the combination of a true population based cancer and death registration scheme enables one to clearly define true incidence and prevalence patterns. Referral patterns to individual institutions may change for many social, political, and cultural reasons, as well as there being genuine increases in incidence. In their study as well, not all of the records were complete and some cases had to be rejected. Furthermore, it is not totally clear why they chose two quite short periods between 1980 and 1982 and 1990 and 1992 to compare incidence of tumour occurrences. There may be some doubt as to whether they are reporting real increases in incidence of individual tumours, or rather just a funny referral pattern during these short periods of time. This may 